\title{
BIOCHAR FROM PLANT MATERIALS WITH A HIGH ABILITY TO DEGRADE OIL PRODUCTS
}

\author{
Khokhlov A. V.
}

\section{INTRODUCTION}

Today, of particular interest is the development of biosorption complexes based on plant materials biomodified by the natural complex of microorganisms-destructors of various pollutants. The natural complex of microorganisms has a wide spectrum of action. The development of a technology for producing a biologically active environmentally friendly sorbent based on plant materials is a promising direction for eliminating oil pollution of water and soil. A study of the adsorption, physico-chemical conditions for the interaction of the sorption matrix with the immobilization of destructive destructive microorganisms has confirmed the advantages of using such biosorption complexes. Moreover, sorption methods are widely used to isolate and concentrate microbial cells of a certain direction. The use of sorbents that absorb biomolecules well and easily precipitate from solutions accelerates the extraction of promising natural microbial cultures capable of using one or another pollutant.

At the development of bioactive oil sorbents it is necessary to take into account both physic-chemical sorbent properties and specificity of oiloxidative microflora. It is known that in the processes of self-purification of natural environment from the oil pollution the leading part belongs to the natural microorganisms. They own high plasticity and have powerful ferment systems, owning to which the pollutants are mineralized and destructed. Immobilization of the oil absorbing sorbent of oil-oxidative microorganisms (OOM) on the surface allows obtainment of the sorption materials of biodestructive type. The sorbent represents the carrying microorganism matrix. The nature of matrix, on which OOM immobilization is executed, effects on the process of destruction of oil products. An effective sorbent - a carrier of microorganisms-destructors should have directed adsorption ability with respect to a pollutant, meet the requirements for absorbents of a certain type, and also be biocompatible.

\section{Bioactive oil sorbents based on plant materials}

Carbon sorbents based on pyrolyzate of cellulose-containing raw materials (wood) among powdered sorbents of natural origin have satisfactory absorption capacity with respect to oil and oil products of various compositions, and most importantly are biocompatible. The surface 
properties of the carbon material were evaluated by indicators determined according to standard methods: specific surface area; the content of acid and carbonyl groups; restoring ability. The concentrations of the adsorbed substance were determined by the gravimetric method and from the calibration graphs by the methods of photometry, UV spectrometry. Based on the results obtained, the physicochemical parameters of the wood pyrolysis process were calculated and the optimal conditions for the production of carbon material were determined. Investigations of some of them have revealed a sufficiently strong intermolecular interaction with the adsorbed substance, which indicates the possibility of regulating the adsorption properties of the carbon material at the production stage. The most important advantages of carbon materials are their resistance and stability in aggressive environments, the ability to adjust the parameters of the porous structure over a wide range. Another advantage is surface inertness, which eliminates the occurrence of unwanted adverse reactions. The biocompatibility of the matrix and microorganisms allows the use of biochar in environmental technologies. It has been established that a biochar based on a pyrolyzate of conifers (pine, fir, spruce) has the best sorption characteristics for oil. The increased content of resinous substances of pine wood during pyrolysis (thermal oxidation) contributes to better hydrophobization of the surface of the formed biochar and the formation of an oleophilic surface. Studies ${ }^{1,2}$, showed that the immobilization of oiloxidizing microorganisms on such a carbon matrix several times increases the destructive ability of microorganisms (Fig. 1) in comparison with other sorbents that are carriers of microorganisms of oil destructors. Sorption properties of sorbents directly depend on the characteristics of raw materials and type of post-processing.

The prospects for using corn-cobs for biochar are due to the fact that its main chemical components are: cellulose, lignin and polysaccharides (pentosans and hectosans).

${ }^{1}$ Chernykh M.S., Sadchikov A.V. Oil destruction and bio-remediation. Modern problems of science and education. 2016. No 5. URL: http://www.scienceeducation.ru/ru/article/view?id=25214

${ }^{2}$ Ivasishin P. Liquidation of oil spillage consequences by bio-decomposing sorbents. Ekologiya proizvodstva. 2009. № 5. P. 67-69. 


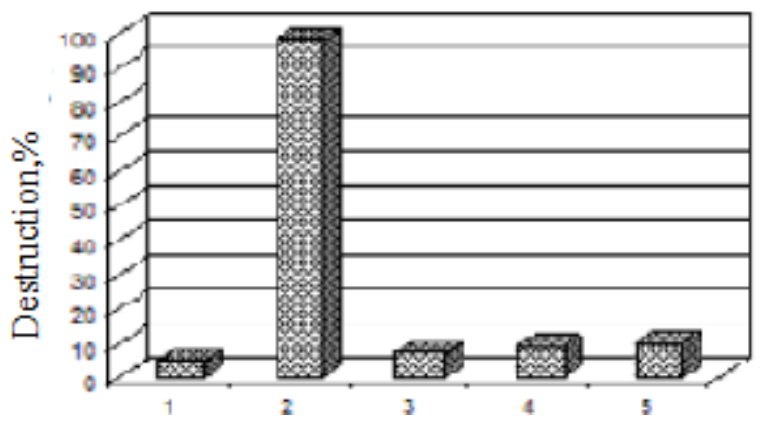

Fig. 1 Efficacy of petroleum products degradation: 1 - complex of oil-oxidative microorganisms (OOM) (the filtrate of culture fluid); 2 - OOM on the carbon matrix; 3-OOM on the perlite; 4 - OOM on the peat; 5 - OOM on the hydrophobic aerosol

Table 1

The comparative chemical content of wood and corn cobs

\begin{tabular}{|c|c|c|c|c|}
\hline \multirow{2}{*}{ Components } & \multicolumn{3}{|c|}{ The percentages of the components } & \multirow{2}{*}{ Note } \\
\cline { 2 - 4 } & Pine & Oak & Corn cobs & \\
\hline Cellulose & 41,93 & 44,17 & $30-34$ & \multirow{3}{*}{$\begin{array}{c}\text { Data from Kenig } \\
\text { and Becker as a } \\
\text { percentage of dry } \\
\text { wood }\end{array}$} \\
\hline Lignin & 29,52 & 23,93 & $15-17$ & $12-15$ \\
\hline Hexosans & 12,78 & 4,06 & $17-20$ & \\
\hline Resin and wax & 10,80 & 24,60 & - & \\
\hline Proteins & 3,17 & 0,68 & 1,58 & \\
\hline Ash & 1,27 & 1,62 & 0,96 & \\
\hline
\end{tabular}

The high content of cellulose and lignin in the structure of corn cobs is similar to the wood in content (Table 1) that allows considering the obtainment of similar carbon material in the process of pyrolysis possible. The data stated in Table 1 evidences about difference between coniferous and broad-leaved types of wood. The coniferous types contain a little more lignin, hectozans and tar. The corn cobs doesn't contain tarry matters. So the obtainment of hydrophobic oil absorbing carbon sorbent requires special approach to preparation of the source raw material and introduction of pyrolysis process. At studying of the properties of corn cobs three its parts, which are distinguished according to the morphological properties: wood ring, cells with scaly crust and core were introduced (Fig. 2). 


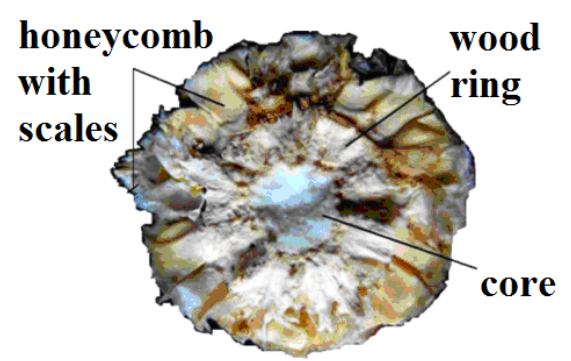

Fig. 2. Structure of corn cobs

The study of peculiarities of wood ring structure showed the presence of developed system of equally distributed hollow pivotal canal (capillaries) with diameter $11.00-64.28 \mu \mathrm{m}$, considerably exceeding the thickness of wall sized ${ }^{3}$ from $1.5-4.5 \mu \mathrm{m}$. The capillaries have the round form and frequently characterize the expressed spiral or ring structure of walls. Based upon this data it is able to suggest the possibility of effective weight transfer in the structures of studied objects that tells about prospect of sorbent obtainment on their basis. The sorption properties of corn cobs and its separate parts were evaluated according to such criteria as floatability, hydrophoby, oil-receptivity and range of working temperatures ${ }^{4}$. The study of different parts of corn cobs showed that the biggest floatability belongs to cob core and cell with scaly crust (more than 70 hours), the smallest - to wood ring. At study of interaction of corn cobs and oil products it was determined that all parts are oil-receptive. For experiment such oil products as oil, diesel oil and processed motor oil were taken. Owing to the structure of closed pores, filled with air, the corn cobs owns high floatability that allows keeping itself on the water surface more than 50 hours.

The results of study showed that the biggest sorption ability belongs to cells with scaly crust and core, but the whole corn cobs owns the sufficient sorption capacity in relation to oil and oil products (Fig. 3, a). The studies on temperature treatment effect of the different corn cobs on sorption properties in relation to oil were studied. In the process of experiment it was established that pyrolized primary raw material (corncobs) has the considerable better indicators of oil-receptivity of surface and sorption properties (Fig. 3, b) in relation to oil. The measurements of statistical angle of material moistening confirmed the change of hydrophoby and

\footnotetext{
${ }^{3}$ Abdel Nasser A., Hendavy El., Samra S.E., Girgis B.S. Adsorption Characteristics of activated carbons obtained from corncobs. Colloids and Surfaces A: Physicochemical. In addition, Eng. Aspects. 2001. P. 180-209.

${ }^{4}$ Tsai W.T., Chang C.Y., Lee S.L. Preparation and Characterization of Activated Carbons from Corn Cob. Ibid. 1997. № 35. P. 1198-1200.
} 
oil-receptivity degree of the surface of primary corn cobs after treatment (pyrolysis).
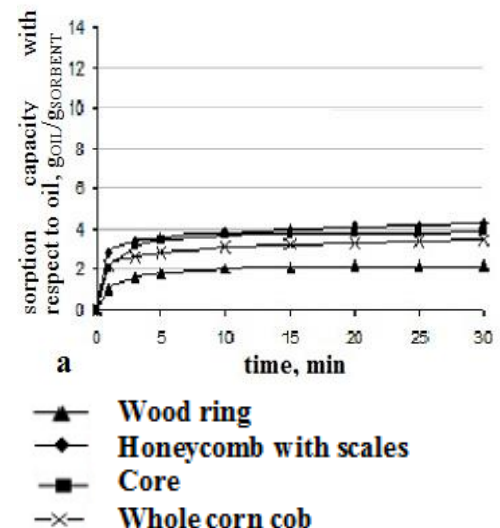

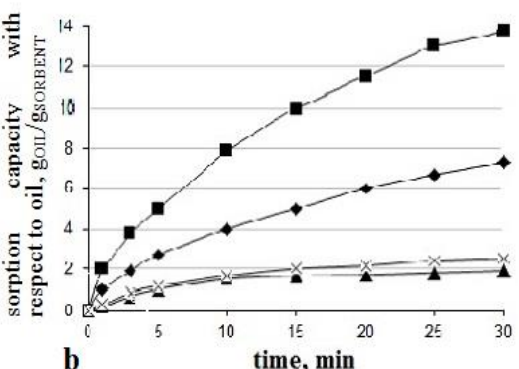

time, min $\dashv$ Pyrolysate from wood ring

$\rightarrow$ Pyrolysate from honeycomb with scales

-- Pyrolysate from core

$-x-$ Pyrolysate from whole corn cob

\section{Fig. 3. Oil capacity of separate parts of corn cobs of the primary raw material (a) and pyrolized (b) one}

The different parts of the ears of corn are either hydrophilic or (ring part) hydrophobic. However, the creation of sorbents based on individual parts of the ears of corn does not seem appropriate; the use of whole ears of corn is real. Pyrolysis of corn cobs increases the degree of hydrophobicity of the material. Upon receipt of the oil-absorbing biochar taking into account further bioactivation, whole corn cobs were used. Obtaining a carbon sorbent from ears of corn has a number of technological features. The sorption capacity of the obtained biochar in relation to oil depends on the parameters of the pyrolysis process of corn cobs and the conditions for the preparation of raw materials. The thermal treatment (pyrolysis) of cellulose-containing raw materials allows the porous structure of the obtained carbon material to be formed and stabilized, as well as to obtain a large volume and a large total proportion of meso and marcopores responsible for the absorption of oil. The temperature and duration of pyrolysis affect the sorption properties of pyrolyzate. Pyrolysis of corn cobs in a strictly functional mode allows to obtain a carbon sorbent with properties based on it in relation to oil and oil products. The pyrolysis of cellulose-containing raw materials is the decomposition of the source material (wood, plant residues) when heated to a certain temperature without air access with the formation of gaseous (liquid) products, as well as solid residues - coal. The final product of complete raw material pyrolysis is almost clean carbon, contained a few potassium, sodium, calcium magnesium and ferric oxides in the form of 
impurities. The free radical reaction of thermal destruction of hemicelluloses, cellulose and lignin, taking place in accordance with 200-260, 240-350 and $250-400{ }^{\circ} \mathrm{C}$ lies in the basis of pyrolysis. The thermal treatment at temperature lower than $250^{\circ} \mathrm{C}$ doesn't allow obtaining the stable porous structure. For such material heating at the next usage can lead to change of parameters of porous structure. The thermal treatment at temperature over $400^{\circ} \mathrm{C}$ leads to some reduction of total volume and change of part of meso- and macropores from the total volume of pores. The structural and chemical transformations in the process of pyrolysis of cellulose containing primary raw material conditions the properties of the obtained carbon material. At thermal oxidation of the primary material in the oxygen-free atmosphere the amorphous carbon is formed. The amorphous modification of carbon in the coal from such raw material was proved before $^{5,6}$. If the time of pyrolysis is not enough, the X-ray (Fig. 4) two wide gallos, typical for cellulose with max 5, 52 and 3,97 $\mathrm{A}^{0}$, are detected amorphous coal structure, ashes formation, crystallization of inorganic. The increase of pyrolysis time and temperature over $400^{\circ} \mathrm{C}$ leads to destruction of compounds properties of carbon material from the corn cobs at the different conditions.

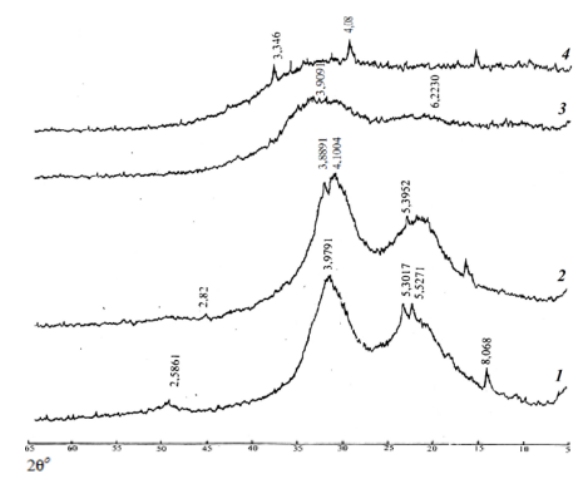

Fig. 4 Diffraction patterns of pyrolysate from corn cobs: 1 - feedstock; $2-250^{\circ} \mathrm{C}, 30$ min.; $3-350^{\circ} \mathrm{C}, 30$ min.; $4-400^{\circ} \mathrm{C}, 30 \mathrm{~min}$.

The optimal conditions of pyrolyzate of the raw material were established in the laboratory conditions for obtainment of the qualitative oil

${ }^{5}$ Lehmann J., Joseph S. Biochar for Environmental Management: An Introduction / ed. by. Biochar for Environmental Management: Science and Technology. London : Routledge 2009. P. 1-12. DOI: https://doi.org/10.4324/9781849770552

${ }^{6}$ Khokhlov A.V. et al Vydalennya naftovykh plivok iz poverkhni vody bioaktyvnymy vuhletsevymy sorbentamy v prysutnosti BIOPAR. Dopovidi NANU. 2005. No. 3. P. 189-192. 
absorbing carbon material, used as matrix for immobilization of oil oxidative microorganisms.

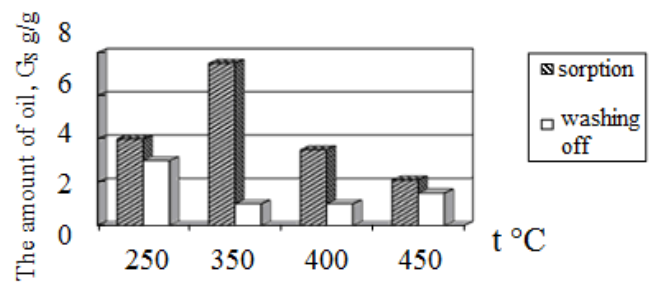

\section{Fig. 5. Influence of pyrolysis temperature on the sorption properties of carbon sorbent from corn cobs}

The optic temperature of pyrolyzate $-300-350{ }^{\circ} \mathrm{C}$, and the pyrolysis is 25-30 min. The oil capacity has the extreme dependence on the pyrolysis time and temperature and achieves the values $5-7,5 \mathrm{~g} / \mathrm{g}$.

The fraction pyrolyzate content also effects on sorption characteristics of carbon sorption matrix. The study of absorption kinetics and washing the absorbed oil from the surface of carbon material from the corn cobs of different disperse content confirmed this dependence. If the fraction with diameter of particles less than $0.25 \mathrm{~mm}$ (to $30-40 \%$ ) prevails in the pyrolyzate, and the sorbent with diameter $0.25-0.5 \mathrm{~mm}$ to $25-30 \%$ has the retaining capacity in comparison to pyrolyzate, where small fractions (less $0.25 \mathrm{~mm}$ ) amount to $15 \%$. At that the primary oil capacity of pyrolyzate has equally valuable meanings.

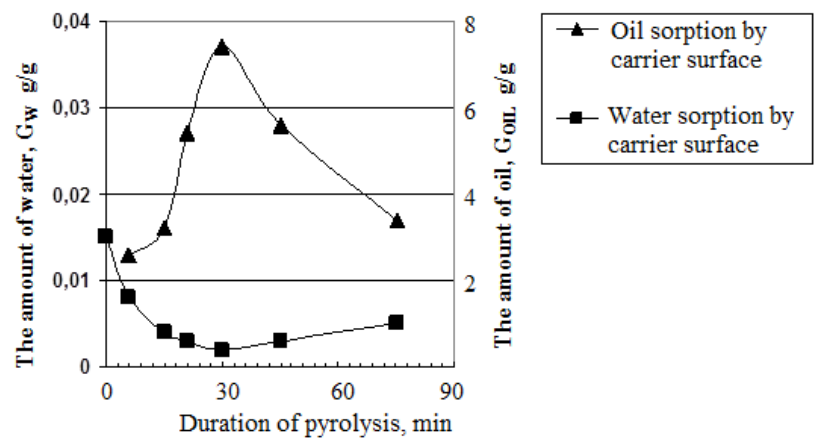

Fig. 6. Influence of duration pyrolysis on the absorption capacity of the carbon material from corn cobs $\left(t p=350^{\circ} \mathrm{C}\right)$ 
The adsorption properties of carbon material are determined by porous structure and chemical nature of surface. The basic characteristics of porous structure of carbon materials are the volume of pores and their distribution according to the sizes. These materials own the high solidity, and developed transitive porosity.

The carbon sorbents on the pyrolyzate of cellulose raw material are characterized with polydisperse porous structure, which have different pores with certain interval of size. At the study of carbon sorbent programmes, the insignificant reduction of the volume and specific surface of mesopores $(2--50 \mathrm{~nm})$ and macropores $(>50 \mathrm{~nm})$ in the carbon sorbent from corn cobs was detected according to the data of mercury porosimetry.

The distribution of pores according to equivalent radiuses of pores of carbon material, obtained from the wood raw material and corn cobs (curves 1 and 2) are almost similar (Fig. 7). The parameters of raw material pyrolysis process from the corn cobs and wood are almost identical.

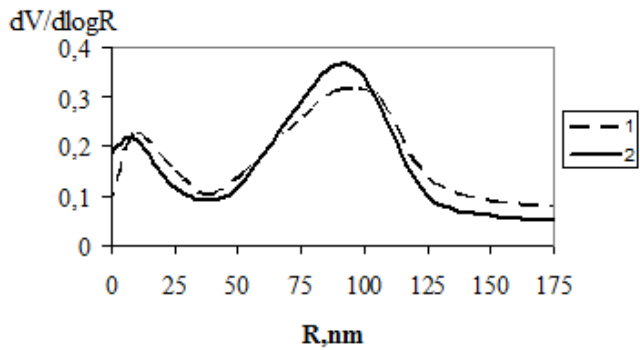

\section{Fig. 7. View of pores of carbon sorptive material-based on pyrolysate corn cobs $\mathbf{- 1}$ and $\mathbf{- 2}$ pyrolysate from wood}

The general porosity of carbon material and distribution of pores according to sizes depends on the pyrolysis temperature and way of previous preparation of raw material - corn cobs. The exit of solid carbon product also depends on these conditions. The maximal exit of carbon material with optimal values of oil capacity is observed at the pyrolysis temperature values $300-350^{\circ} \mathrm{C}$.

The nature of carbon sorbent surface affects both on sorption properties, and on the possibility and character of immobilization of microorganisms oil destructors on the surface of sorption material. The reactive capable groups are created in the process of formation of carbon material at pyrolysis of cellulose containing material on the coal surface. The concentration of the functional (carboxyl and phenol) groups on the carbon material surface 
conditions the ability to retain biomolecules on the surface owing to covalent connection or due to $-\mathrm{COOH}-,-\mathrm{COCl}-,-\mathrm{NH}_{2}-,-\mathrm{N}_{2}{ }^{+}$и $-\mathrm{NCO}-$ groups ${ }^{7}$.

IR-spectroscopic studies of carbon sorbent from the corn cobs showed the reduction of band intensity $\left(1200-1300 \mathrm{~cm}^{-1}\right)$, responsible for fluctuations of phenol groups and band intensity $\left(1700-1750 \mathrm{~cm}^{-1}\right)$, typical for carboxyl groups at bioactivation of primary sorption matrix ${ }^{8}$. The surface interaction of sorption matrix with oil destructing biocomplex takes place. This fact confirms the possibility of using carbon material from corn cobs to obtain a bioactive oil-absorbing sorbent of a destructive type, similar to a biosorbent from wood.

The study of structural characteristics of primary carbon sorption matrix and bioactivated one from the corn and wood raw material showed the similar changes of specific surface and quantity of protogene oxygen containing functional groups (Table 2). The absorbed biomolecules are retained on the carrier surface owing to Van der Waals forces, hydrogen connections and hydrophobic interaction.

The peculiarities of obtainment of carbon sorbent from the corn cobs, as it was stated above, were also conditioned by the content of this raw material. The studies conducted earlier showed that at pyrolysis of coniferous wood the tarry matters are separated. Thermal oxidation of the pine-tree allows obtaining the charcoal in the functional regime, where the framework is saturated with tar. Unsaturated carbon atoms are connected with molecules of tarry matters. At that the surface of carbon, obtain at pyrolysis of coniferous wood, become hydrophobic and shows oil-receptive properties ${ }^{8}$. So, pyrolyzate has better sorption characteristics in relation to oil.

As the corn cobs in the pyrolysis process doesn't separate tarry matters, the additional material treatment with water-repellent agent was conducted at preparation of raw material from the corn cobs. Hydrophobization adds hydrophoby and humidity resistance to the material. Water-repellent agent must: have high chemical and atmospheric stability; be cost-effective and sage for a human. Application of synthetic tars, paraffins, and oil chemistry products doesn't satisfy the above listed characteristics.

Hydrophobization is applied on porous materials for enhancement of their hydrophoby and provision with oil-receptive properties. The contents on the basis of silicon compounds form the thinnest unwashed film adding the oil-receptive properties to the surface in the pores and on the material surface.

${ }^{7}$ Ostrovidova G.U., OV Denisova O.V., Fadeeva I.I. Investigation of Properties of dispersed carbon carriers of biologically active substances. J. Fiz.Chemistry. 1990. № 8. P. 2157-2161

Khokhlov A., Khokhlova L. Carbon Sorbent of Destructive Type Based on Wood Biochar for Removal of Oil Pollution. J. Environ Anal Toxicol. 2018. T. 8 (4): 576. DOI: 10.4172 / 2161-0525.1000576 
Structural characteristics of the original carbon matrix and bioactivated matrix from wood and corn cobs

\begin{tabular}{|c|c|c|c|c|}
\hline \multirow{2}{*}{ The indicator } & \multicolumn{2}{|c|}{ Carbon sorptive matrix } & \multicolumn{2}{c|}{$\begin{array}{c}\text { Bioactivated carbon } \\
\text { sorbent }\end{array}$} \\
\cline { 2 - 5 } & $\begin{array}{c}\text { From } \\
\text { wood }\end{array}$ & $\begin{array}{c}\text { From } \\
\text { corn cobs }\end{array}$ & $\begin{array}{c}\text { From } \\
\text { wood }\end{array}$ & $\begin{array}{c}\text { From corn } \\
\text { cobs }\end{array}$ \\
\hline Specific surface, $\mathrm{m}^{2} / \mathrm{g}$ & $60-80$ & $55-70$ & $45-55$ & $40-52$ \\
\hline $\begin{array}{c}\text { Static exchange capacity for } \\
\mathrm{NaOH}, \mathrm{mg}-\mathrm{equ} / \mathrm{g}\end{array}$ & 5,1 & 4,8 & 3,5 & 3,1 \\
\hline $\mathrm{Vs}\left(\mathrm{C}_{6} \mathrm{H}_{6}\right), \mathrm{sm}^{3} / \mathrm{g}$ & 0,12 & 0,11 & 0,08 & 0,07 \\
\hline $\mathrm{Vs}\left(\mathrm{H}_{2} \mathrm{O}\right), \mathrm{sm}^{3} / \mathrm{g}$ & 0,08 & 0,08 & 0,05 & 0,04 \\
\hline
\end{tabular}

Notes: Vs (C6H6) - porosity, pore volume expressed as sorption on benzol; Vs (H2O) porosity, expressed as sorption water pore volume; $S E C$ - static exchange capacity

Polyhydroxyloxane-type organic silica compounds in various dilutions were used as a surface hydrophobizing agent to obtain a hydrophobic carbon material from corn cobs. When the surface is hydrophobized with solutions of organic silica compounds, which have a sufficiently low viscosity and surface tension, they penetrate deeply into very small pores of the material. The penetration depth is much higher since the surface tension and viscosity of the waterrepellent agent are lower and the porosity of the material is higher.

Table 3

Comparative structural and sorption characteristics of a biochar based on wood and corn cobs under hydrophobization conditions (pyrolysis temperature $-350^{\circ} \mathrm{C}$, pyrolysis time $-30 \mathrm{~min}$.)

\begin{tabular}{|c|c|c|c|}
\hline \multirow{2}{*}{ The indicator } & \multicolumn{3}{|c|}{ The type of pyrolysate } \\
\cline { 2 - 4 } & Pine & $\begin{array}{c}\text { Corn cobs } \\
\text { without liquid for } \\
\text { hydrophobisation }\end{array}$ & $\begin{array}{c}\text { Corn cobs } \\
\text { processed by } \\
\text { liquid for } \\
\text { hydrophobisation }\end{array}$ \\
\hline Hydrophobicity, \% & $98-95$ & $20-30$ & $80-90$ \\
\hline $\begin{array}{c}\text { Sorption capacity with respect to } \\
\text { oil, g oil/g sorbent }\end{array}$ & $8,0-10,0$ & $2,0-3,0$ & $6-7,5$ \\
\hline $\begin{array}{c}\text { Static exchange capacity, mg- } \\
\text { equ/g (SEC) }\end{array}$ & $3,2-5,1$ & $2,1-2,5$ & $2,2-2,9$ \\
\hline Specific surface, $\mathrm{m}^{2} / \mathrm{g}$ & $60-80$ & $50-60$ & $45-65$ \\
\hline $\mathrm{Vs}\left(\mathrm{H}_{2} \mathrm{O}\right), \mathrm{sm}^{3} / \mathrm{g}$ & $0,08-0,10$ & $0,11-0,13$ & $0,07-0,09$ \\
\hline $\mathrm{Vs}\left(\mathrm{C}_{6} \mathrm{H}_{6}\right), \mathrm{sm}^{3} / \mathrm{g}$ & $0,09-0,12$ & $0,08-0,12$ & $0,07-0,11$ \\
\hline
\end{tabular}

The optimal conditions for the pyrolysis of raw materials based on corn cobs to establish a high-quality oil-absorbing biochar used as a matrix for immobilizing oil-oxidizing microorganisms are established. The optimal pyrolysis temperature is $300-350^{\circ} \mathrm{C}$, and the pyrolysis time is 25-30 minutes with the obligatory treatment of primary corn cobs with a water-repellent composition (Table 3). 
The biochar based on pine pyrolyzate has a number of improved structural characteristics $\left(\mathrm{COE}, \mathrm{BC}\left(\mathrm{C}_{6} \mathrm{H}_{6}\right), \mathrm{BC}\left(\mathrm{H}_{2} \mathrm{O}\right)\right)$ and oil absorption capacity. Determining the suitability of sorption material for a specific purpose, namely, to obtain an oil-absorbing bioactive sorbent, requires a study of their physicochemical characteristics. Establishing a relationship between the structural features and sorption properties of the material determines its use both as an oil-absorbing sorbent and as a carrier for immobilizing oil-oxidizing microorganisms in the creation of biodestructive oil sorbents. The biochar quality criteria are sorption properties, which were evaluated by oil conductivity (the number of grams of oil absorbed by one gram of sorbent) and which retains the ability of absorbed oil on the surface.

The porous structure and chemical nature of the surface of the btochap matrix based on the pyrolyzate of cellulose-containing raw materials of both wood and corn cobs determines its sorption properties with respect to petroleum hydrocarbons. However, the dominant factors in the relationship between the carbon material and oil are hydrophobic interactions. According to, intermolecular interaction plays a significant role in adsorption phenomena, where the main role belongs to nonpolar hydrophobic groups ${ }^{9}$. The specific features of hydrophobic interaction are explained by the physical nature of the surface. The physical nature of the hydrophobic interaction has three main detection criteria. The first criterion is the weakening (or intensification) of hydrophobic interaction by introducing appropriate electrolytes into the system. The second is the weakening of hydrophobic interaction with organic solvents. Third, increased hydrophobic interaction with increasing temperature.

Water - oil - biochar is a heterogeneous system. The hydrophobic interaction in such a system depends on the nature of the sorbent particles and the degree of their hydrophobicity. Pine pyrolyzate is characterized by 98\% hydrophobicity, and corn cobs pyrolyzate without hydrophobizator has a hydrophobicity of up to $30 \%$, but when using a hydrophobicizer, hydrophobicity reaches $90 \%$. The behavior and properties of the system in which hydrophobic particles are present are determined by the complete hydrophobic interaction between the hydrophobic particles of the carbon sorption material and oil hydrocarbons.

On fig. 8 shows the oil resistance biochar matrix with increasing ambient temperature from normal conditions $20^{\circ} \mathrm{C}$ to $50^{\circ} \mathrm{C}$. An increase in temperature leads to an increase in the sorption capacity of the material (third criterion) due to an increase in hydrophobic interaction. The introduction of an organic solvent into the system $\left(\mathrm{CCl}_{4}\right)$ reduces the sorption capacity of the biochar absorbent (second criterion). These studies confirm the presence of hydrophobic interaction of biochar-sorbent-oil, as the main factor in the oil absorption capacity of the sorption material.

\footnotetext{
${ }^{9}$ Khokhlov A., Strelko V., Khokhlova L. Physico-chemical features of bioactive carbon sorbents for oil. Chemistry and Chemical Technology. 2018. Vol. 12. No. 3. P. 337340 DOI: https://doi.org/10.23939/chcht12.03.337
} 


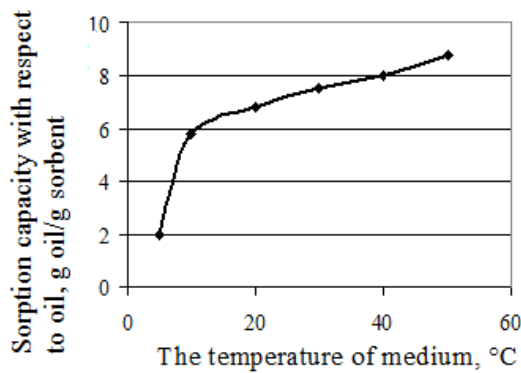

Fig. 8. Influence of environmental temperature on the ability to absorb oil by carbon material made from corn cobs

Studies of the structural and sorption properties of biochar obtained by pyrolysis of corn cobs, compared with biochar, obtained from coniferous wood for biosorbent, indicate the possibility of using such a material as a matrix for immobilization of oil destructive microorganisms in the production of bioactive oil bio sorbents.

In fig. 9 presents the results of electron microscopic studies of a primary sorption matrix based on pyrolyzate of corn cobs and during the immobilization of oil destructive microorganisms. The images show an active process of oxidative microflora growth in the presence of oil (photo 3 ). This fact indicates the possibility of using corn cobs in obtaining a biosorbent of a destructive type for oil.

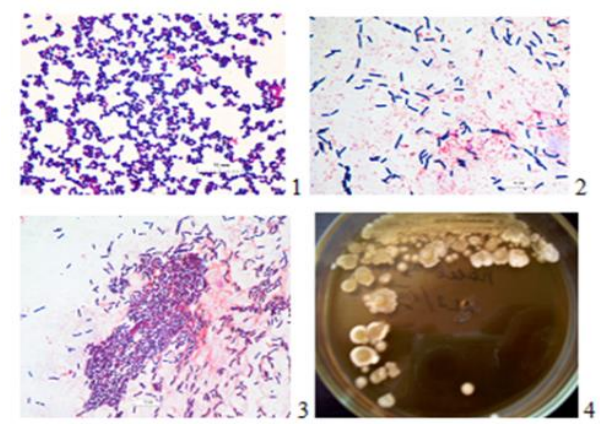

Fig. 9. The growth of oil-destroying microorganisms during immobilization on a carbon carrier from ears of corn: 1) biochar;

2) biochar with immobilized MO without oil; 3) biochar with immobilized MO in oil; 4) the growth of isolated MO-destructors on petroleum jelly in the environment of meat-peptone agar 
A biochar based on corn cobs pyrolyzate absorbs oil and oil products and exhibits biocompatibility with oxidizing microorganisms. Moreover, in all measures related to eliminating the effects of oil pollution and restoring oilpolluted ecosystems, it is necessary to rely on the main principle: not to damage the ecosystem to a greater extent than damage already done to it. pollution. An oil sorbent based on the pyrolyzate of corn cobs and microorganisms immobilized (fixed) on its surface (oil destructors extracted from natural objects) ensures the environmental safety of using such a biosorption complex. An integrated approach to solving the problem of eliminating oil pollution - sorption + oil destructors can increase the efficiency and environmental friendliness of work.

\section{Features of the immobilization of microorganisms - destructors of oil on biochar surface}

A biochar from gastronomic raw materials is sorption active both for oil and for microorganisms-destructors of oil. These properties determine the possibility of its use as a matrix for immobilization of a microbial oil-oxidizing complex. The quality and destructive activity of bioactive sorbents depends not only on the choice of carrier type, but also largely on the type that destroys the ability of microorganisms, as well as on the method of their immobilization.A natural consortium of effective oil-oxidizing microorganisms includes aerobic and microaerophilic species with similar dynamic relationships. Under natural conditions, the positive properties of combined microorganisms accumulate. If there is an organic nutrient (oil), there is a continuous reproduction of bioculture, generating the useful power of the biocomplex for cleaning the environment from oil products. The development of microorganisms and the intensity of their activity are determined by environmental conditions ${ }^{10,11}$. The leading factors are the composition of hydrocarbons, temperature and the rate of water exchange in the environment. To obtain a microbial complex of natural origin, studies were conducted on the isolation, selection of oil-oxidizing microbiota from samples of oil-contaminated soils, wastewater, oil traps of sewage treatment plants, silt deposits of oil sludge collectors, sediments from sedimentation tanks of used drilling fluids of industrial oil facilities. Our studies of the presence of oiloxidizing groups of microorganisms in various objects of pollution showed that wastewater samples were populated by OOM in the amount of 440-780 thousand cells per $1 \mathrm{ml}$. The number of hydrocarbon-oxidizing microorganisms in soil samples did not differ significantly - 120-670 thousand cells per $1 \mathrm{~g}$ of soil. Microorganisms are also widespread in oil-contaminated

${ }^{10}$ Volde M.I. The ecological mechanism of the action of glucose on the activity of hydrocarbon-oxidizing microorganisms in the soil / Abstract. diss. Moscow State University. 2002. 25 p.

${ }^{11}$ Patent No. 43965A UA.. A consortium of microorganisms for the purification of surface water environments and soils from oil and oil products. Khokhlova L.I., Shvets D.I., Khokhlov A.V. Publ. 01/15/2002. Bull. № 1 
drilling fluids, their number is $400-460$ thousand cells per $1 \mathrm{~g}$, in the sediment of oil sludge collectors - 440-610 thousand cells per $1 \mathrm{~g}$. Wastewater, oilcontaminated soil, spent drilling fluids, sedimentation reservoir sludge is a constant component of microbial cenosis and a source of supply for OOM. OOM accumulative cultures were grown on ordinary elective media at temperatures of $32-35^{\circ} \mathrm{C}$ and $20-25^{\circ} \mathrm{C}$, taking into account the optimum of their development. The ability of microorganisms to assimilate hydrocarbons of aliphatic and aromatic series was determined on an agarized mineral medium in the presence of one or another hydrocarbon oil. Adaptation of the microbial natural mixture to various conditions (temperature, chemical composition of oil and others) generates biodestructive effectiveness of the entire group of oiloxidizing microorganisms with a wide spectrum of action. For the bioactivation of the carbon carrier, the most active component of the native culture was selected. Microbial colonies were obtained from the inoculum by enrichment and selection on a nutrient medium of a certain composition. The enrichment was carried out over a wide temperature range from 4 to $30^{\circ} \mathrm{C}$ for various types of oil and oil waste. The resulting microbial suspension was adapted to aerobic and microarophilic conditions, to low temperatures. The rate of bacterial action depends on the size of the total surface of hydrocarbons that are decomposed by microorganisms. The greatest activity activity is manifested in the dispersion of hydrocarbons, when the largest plane of contact surface is provided per unit mass, because bacteria exist and feed mainly in the aquatic environment and act only when water and hydrocarbons come into contact. Dispersion or emulsification of hydrocarbons contributes to the active development of biocenosis. Thus, the immobilization of OOM on the surface of the sorbent provides the elective conditions for the biodegradation of oil in the sorbed state.

Cells located on the interface between solid and liquid phases have the necessary power source (sorbed oil) and better energy development conditions than in the case of a homogeneous state of oil. In order for oil to undergo biodegradation actively, it must be dispersed or emulsified. Sorbent acts as a dispersant in the system. The cultivation of microorganisms in pores on the surface of the carrier imitates their natural existence. Cellular immobilization is a process in which cells attach to a surface where the hydrodynamic characteristics differ from the characteristics of the environment. Immobilization of cells can be a natural process or can be realized by chemical or physical methods. Cellular immobilization allows you to create bioparticles of different sizes, volumes and densities and allows you to achieve a significant concentration of cells. The nature of the surface of the carrier affects both the nature of the immobilization of biomolecules and the sorption, catalytic properties of the bioactivated sorption material. In the process of biochar formation during pyrolysis on the surface of coal, as mentioned above, reactive groups are created. The concentration of functional (carboxyl and phenolic) groups on the surface of the carbon material determines the ability to hold biological molecules on the surface. 
The ability to use hydrocarbons as the only energy source allows the microorganisms-destructors that attach to the surface to directly carry out biodegradation of oil and oil products localized on biosorbent. The possibility of using a bioactivated carbon sorbent to remove oil and oil products from surface water, soil and other surfaces has been studied. The study of sorption and biodegradation of oil and oil products of various compositions, including highly oxidized products. We studied the hydrocarbon composition of crude oil, diesel fuel, oil sludge (oil residue), resin before and after treatment with biosorbent. The hydrocarbon composition of petroleum products was studied by column and gas-liquid chromatography. The main components of crude oil are n-saturated hydrocarbons, aromatic hydrocarbons. In partially oxidized oil, n-saturated hydrocarbons are practically absent, but there are more asphaltene fractions. Oil sludge is a stable oil emulsion. The bulk of oil sludge hydrocarbons are heavy aromatic and paraffin-naphthenic hydrocarbons (31-83\%), resins (10-44\%) and asphaltenes (4-14\%). A wide range of physico-chemical properties of oil sludge, various conditions for the receipt and storage determine the methods for their disposal.

A comparative determination of the residual amount of oil (extraction and photocolorimetric measurements) and bacterial turbidity (measurements of turbidity or dry biomass weight after centrifugation) make it possible to characterize the development of microbial substance and the degree of biodegradation of oil. The rate of microbial decomposition of oil localized on the surface of the sorbent was much higher than the biodegradation of a continuous layer of oil on the water surface (Fig. 10) with the same amount of inoculum oil oxidizing cultures of $120-200 \times 10^{4}$ cells / $\mathrm{g}$ and oil $(8 \mathrm{~g})$ in the system.

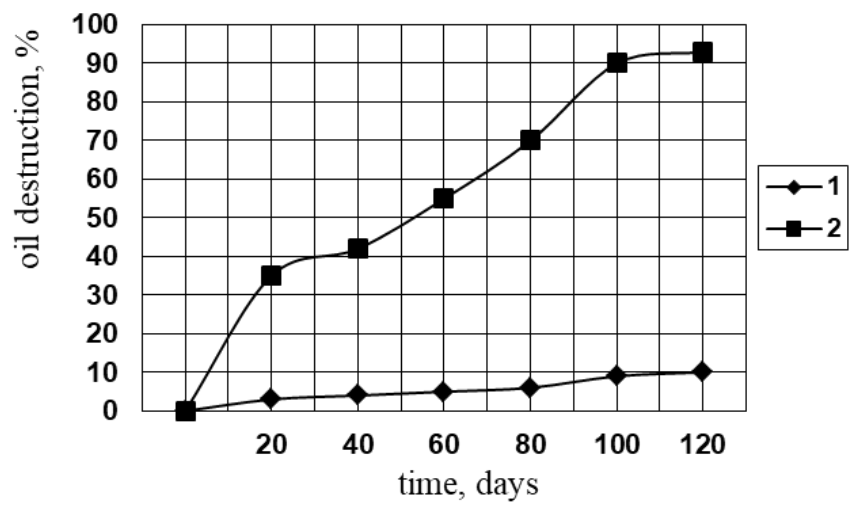

Fig. 10. Kinetics of oil destruction on the surface of water (1) and adsorbed on biosorbent (2) 
The most important conditions for the development of biocenosis are the amount of OOM on the sorbent and the ambient temperature. The amount of bacterial culture, as noted earlier, affects the quality of sorption of the biosorbent. The optimal concentration of the microbial component on the carbon matrix is $120-200 \times 10^{4}$ cells / $\mathrm{g}$ with a maximum oil sorption of $8 \mathrm{~g} / \mathrm{g}$. The temperature of the medium affects the rate of decomposition of petroleum hydrocarbons and the nature of the products that form during biodegradation. The metabolic process is regulated by enzymes that have a different temperature optimum. For most oiloxidizing microorganisms, the optimum development temperature is $25-30^{\circ} \mathrm{C}$. When creating a biosorbent, a complex of oil-oxidizing microorganisms is necessary, which was immobilized on a carbon carrier and was adapted to temperature fluctuations. Chromatographic studies of oil products sorbed by the biosorbent, their concentration and group composition before and after biodegradation confirmed the course of the biodegradation of oil products localized on the biosorbent and changes in the group composition of residual oil products. Using a consortium of oil-oxidizing microorganisms from the environment has several advantages: firstly, the original natural population is well adapted to environmental conditions; secondly, having high stability and synergism, it is able to provide a more complete use of the target substance as the sole source of nutrition; thirdly, the return of the microorganism to its original environment gives this organism a selective advantage.

\section{CONCLUSIONS}

The possibility of using a biochar as a matrix - a carrier of OOM upon receipt of a biosorbent is substantiated. Firstly, the carbon material meets the requirements for oil sorbents - environmental friendliness, oil intensity (8-12 $\mathrm{g}$ of oil per $1 \mathrm{~g}$ of sorbent), manufacturability. Secondly, this material is biocompatible.

It is shown that under optimal pyrolysis conditions of coniferous wood raw materials a biochar is formed, the skeleton of which is impregnated with resin. In this case, the surface of the carbon material becomes hydrophobic, exhibits oleophilic properties. Biochar corn cobs requires additional hydrophobization. The porous structure and chemical nature of the surface partially determine the oil-absorbing ability of the material, but th dominant factor is the interaction of the hydrophobic surface with petroleum hydrocarbons.

It was shown that a universal oil-oxidizing microbial complex, isolated from natural oil-contaminated objects, is able, together with a biochar, to neutralize oil pollution of various types and concentrations. The degree of destruction of more than $95 \%$. The special and adapted OOM complex is resistant to temperature fluctuations.

Assessment of the destructive activity of the developed biosorbent in relation to petroleum products of various chemical composition. It was found that microorganisms - oil destructors, immobilized on the surface of the biosorbent, 
are able to decompose almost all oil hydrocarbons. The biooxidation rate decreases in a row: diesel fuel - crude oil - oil - oil sludge - tar.

The features of the removal and disposal of oil pollution for various objects: the surface of reservoirs, soil, solid surfaces. On water surfaces, biosorbent is used in quantities based on the calculation of the volume of oil. Sophisticated technology is used to neutralize petroleum products fixed on soil particles or on a solid surface (concrete, coatings). The use of a demulsifier in this case makes it possible to extract oil products fixed on soil particles or on any surface and create conditions for biodegradation. The composition based on the biosorbent has adsorption, physico-chemical and biological activity with respect to heavy non-volatile hydrocarbon oils fixed on a solid surface.

The use of an environmentally friendly bioactive carbon sorbent of complex action based on pyrolyzate of wood raw materials and immobilized natural varieties of oil-oxidizing microorganisms with a wide spectrum of action allows to localize oil pollution and neutralize it as a result of biodegradation. Biosorbent does not require removal from places of use and disposal; independently used for 3-6 months.

\section{SUMMARY}

The expediency of using a biochar from wood and corn cobs as a matrix - a carrier of microorganisms of oil destructors in the preparation of a biosorbent is substantiated. The biochar meets the requirements for oil sorbents - environmental friendliness, oil consumption (8-12 $\mathrm{g}$ of oil per $1 \mathrm{~g}$ of sorbent), manufacturability and biocompatibility. The porous structure and chemical nature of the surface partially determine the oil-absorbing ability of the material, but the dominant factor is the interaction of the hydrophobic surface with petroleum hydrocarbons. A universal oil-oxidizing microbial complex isolated from natural oil-contaminated objects is able to neutralize oil pollution of various types and concentrations together with a carbon carrier. It was found that microorganisms - oil destructors, immobilized on the surface of the biosorbent, are able to decompose almost all oil hydrocarbons. The use of a bioactive carbon sorbent based on a biochar and immobilized natural oil-oxidizing microorganisms with a wide spectrum of action allows localizing oil pollution and neutralizing it due to biodegradation. Biosorbent does not require removal from places of use and disposal; it is independently utilized.

\section{REFERENCES}

1. Chernykh M.S., Sadchikov A.V. Oil destruction and bio-remediation. Modern problems of science and education. 2016. No. 5. URL: http://www.science-education.ru/ru/article/ view?id=25214

2. Ivasishin P. Liquidation of oil spillage consequences by bio-decomposing sorbents. Ekologiya proizvodstva. 2009. No. 5. P. 67-69. 
3. Abdel Nasser A., Hendavy El., Samra S.E., Girgis B.S. Adsorption Characteristics of activated carbons obtained from corncobs. Colloids and Surfaces A: Physicochemical. In addition, Eng. Aspects. 2001. P. 180-209.

4. Tsai W.T., Chang C.Y., Lee S.L. Preparation and Characterization of Activated Carbons from Corn Cob. Ibid. 1997. 35. P. 1198-1200.

5. Lehmann J., Joseph S Biochar for Environmental Management: An Introduction / ed. by. Biochar for Environmental Management: Science and Technology. London : Routledge 2009. P. 1-12. DOI: https://doi.org/10.4324/9781849770552

6. Khokhlov A.V. et al Vydalennya naftovykh plivok iz poverkhni vody bioaktyvnymy vuhletsevymy sorbentamy v prysutnosti BIOPAR. Dopovidi NANU. 2005. No. 3. P. 189-192.

7. Ostrovidova G.U., OV Denisova O.V., Fadeeva I.I. Investigation ofProperties of dispersed carbon carriers of biologically active substances. J. Fiz. Chemistry. 1990. № 8. P. 2157-2161.

8. Khokhlov A., Khokhlova L. Carbon Sorbent of Destructive Type Based on Wood Biochar for Removal of Oil Pollution. J Environ Anal Toxicol. 2018. Vol. 8 (4): 576. DOI: 10.4172 / 2161-0525.1000576

9. Khokhlov A., Strelko V., Khokhlova L. Physico-chemical features of bioactive carbon sorbents for oil. Chemistry and Chemical Technology. 2018. Vol. 12. No. 3. P. 337-340. DOI: https://doi.org/10.23939/ chcht12.03.337

10. Volde M.I. The ecological mechanism of the action of glucose on the activity of hydrocarbon-oxidizing microorganisms in the soil / Abstract. diss. Moscow State University. 2002. 25 p.

11. Patent No. 43965A UA. A consortium of microorganisms for the purification of surface water environments and soils from oil and oil products. Khokhlova L.I., Shvets D.I., Khokhlov A.V. Publ. 01/15/2002. Bull. № 1.

Information about author: Khokhlov A. V., Candidate of Technical Sciences, Senior Researcher of the Department of Ecological Chemistry Institute for Sorption and Problems of Endoecology of the National Academy of Sciences of Ukraine 13, Generala Naumova str., Kyiv, 03164, Ukraine 